\title{
O EVOLUCIONISMO ECONÔMICO NA PÓS-GRADUAÇÃO BRASILEIRA: UMA ANÁLISE A PARTIR DA ÓTICA DA EDUCAÇÃO
}

\author{
Evandro Dotto Dias*; Rodrigo Rorato**
}

Recebido: 22 jun. 2012

Aprovado: 6 dez. 2012

*Universidade Federal Santa Maria. Santa Maria, RS, Brasil. Contato: evandrodotto@ufsm.br

** Universidade Federal Santa Maria. Santa Maria, RS, Brasil. Contato: roratto_rs@hotmail.com

Resumo: As transformações proporcionadas pela globalização da economia influenciaram a pós-graduação brasileira, onde a pesquisa acadêmica passou a ocupar um ponto estratégico no Plano Nacional de Pós-Graduação (PNPG, 2011-2020), sendo considerada como uma poderosa ferramenta para o desenvolvimento econômico do país. Essa visão desenvolvimentista vai ao encontro da escola do pensamento econômico neoschumpeteriana (evolucionista), que preconiza a conjugação do conhecimento e aprendizado, com o estímulo à Pesquisa e Desenvolvimento (P\&D), como fundamental à geração de inovações no sistema produtivo, e logo ao progresso tecnológico das nações. Diante desse contexto, este artigo apresenta uma análise crítica a essa formatação (economicista) presente no sistema de avaliação da pós-graduação brasileira, com base na concepção teórica de expoentes clássicos e contemporâneos da área de educação. Com isso, verificou-se a reificação do conhecimento e a (trans)formação do sujeito (docente-pesquisador), como um agente empreendedor, em detrimento de sua essência social, de sua consciência-de-si e da educação como um todo, dentro de um espectro in vivo, segundo a visão hegeliana. Além disso, constatou-se a pouca relevância dos demais pilares universitários, como ensino e extensão, com o direcionamento das políticas estatais para o fomento à pesquisa acadêmica voltada ao desenvolvimento econômico e à formação de produto(s) e produtor(es).

Palavras-chave: Desenvolvimento econômico e progresso (tecnológico). Pesquisa acadêmica. (Trans)formação do sujeito.

Economic Evolutionism in the Brazilian Graduate Studies:

An Analysis from the Vantage Point of Education

Abstract: The transformations offered by globalization of the economy influenced graduate programs, where academic research has occupied a strategic point in the National Graduate Studies Plan (PGNP, 2011-2020), considered as a powerful tool for the economic development of the country. This developmental view is consistent with the neoschumpeterian school of economic thought (evolutionary), which advocates a combination of knowledge and learning with the encouragement of research and development ( $R$ \& D), as fundamental to the generation of innovations in the productive system, and the technological progress of nations. In this context, the paper presents a critical analysis of this economicistic format of the present graduate program evaluation system, based on the theoretical concept of exponents of classical and contemporary education. Thus, what is verified is the reification of knowledge and the (trans) formation of the teacher-researcher into an entrepreneur, detrimental to his social essence, his self-consciousness and to education as a whole, within a spectrum in vivo, according to the Hegelian view. Furthermore, there is little relevance placed on other academic pillars, such as teaching and extension, with the emphasis of state policies on the promotion of academic research focused on economic development and the formation of product (s) and producer (s).

Keywords: Economic development and progress (technology). Academic research. (Trans)formation of the subject. 
A despeito dessa natureza 'platônica' do saber, a racionalidade de um juízo não implica sua verdade, apenas sua aceitabilidade num contexto dado

(HABERMAS, 2007).

\section{INTRODUÇÃO}

As transformações ocorridas no capitalismo mundial nos últimos quarenta anos abriram um novo momento histórico relativo ao próprio sistema capitalista, ocasionando transformações para além da esfera produtiva e econômica. Assim, estas mudanças refletiram-se também na organização social, política, cultural, e consequentemente, educacional das nações em todo o mundo. Estas mudanças também chegaram à academia, influenciando diretamente o posicionamento estratégico da pesquisa acadêmica como um fator predominantemente voltado ao desenvolvimento econômico, conforme pode ser observado no Plano Nacional de Pós-Graduação - PNPG (BRASIL.MEC, 2010, p. 18):

O núcleo da pós-graduação é a pesquisa. A pesquisa depende de treinamento e exige dedicação plena ao estudo, sendo a tarefa das instituições acadêmicas e institutos de pesquisa, públicos ou privados, aliar este e aquela. Os resultados da pesquisa, ao serem aplicados, levam a novas tecnologias e a procedimentos, podendo ser usados no setor público e no sistema privado, e fazendo do conhecimento e da tecnologia uma poderosa ferramenta do desenvolvimento econômico e social.

Essa visão estatal vai ao encontro das bases da escola do pensamento econômico neoshumpeteriana, também denominada de escola evolucionista, pois propõe que o conhecimento e aprendizado quando combinados podem levar à geração de inovação, tão necessária ao crescimento econômico como um todo. Dosi (1984), seguidor dessa teoria, afirma que o conhecimento é importante não apenas por si só, como também por todos os seus desdobramentos, uma vez que o processo de busca de melhorias tecnológicas e organizacionais em cada firma é um processo cumulativo, ou seja, quanto mais se conhece, mais se está apto para prosseguir com a aquisição de novos conhecimentos e, sendo o processo cumulativo, aprendizados anteriores são necessários para a obtenção de novos conhecimentos, sendo fundamental, portanto, o constante investimento no processo de aprendizagem.

Devido a essa dependência fundamental do aspecto econômico de coisas sobre tudo mais, não é possível explicar uma mudança eco- 
nômica através somente de condições econômicas prévias. Isso porque o estado econômico de um povo não emerge simplesmente de condições econômicas anteriores, mas de toda a situação anterior... (SCHUMPETER, 1957, p. 64).

Mas se a geração de conhecimento acadêmico através da pesquisa tem no desenvolvimento econômico o principal objetivo, onde está a universalidade na universidade? Estaria reduzida ao direcionamento instrumental das políticas produtivas do conhecimento "útill", e justificação de rankings, "periodizada" nas classificações trienais dos Programas de Pós-Graduação, pela ótica avaliativa da Coordenação de Pessoal de Nível Superior - CAPES?

A academia, um lugar de formação e transformação voltado para a constituição do sujeito como agente de mudança social e elevação cultural, ou mais uma ferramenta estratégica da economia? Será que há uma a inversão de papéis, em relação à educação acadêmica a serviço da economia, portanto, um produto e resultado da incessante busca de inovação?

Essa preocupação com o fim ou os resultados, como também com as diversidades e apreciações dos mesmos, é, pois, uma tarefa mais fácil do que talvez pareça. Com efeito, tal [modo de] agir, em vez de se ocupar com a Coisa mesma, passa sempre por cima. Em vez de nela demorar-se e esquecer a si mesmo, prende-se sempre a algo distinto; prefere ficar em si mesmo a estar na Coisa e a abandonarse a ela. Nada mais fácil que julgar o que tem conteúdo e solidez; apreendê-lo é mais difícil; e o que há de mais difícil é produzir sua exposição, que unifica a ambos (HEGEL, 1992, p. 23).

O docente como empreendedor ou empreendedor versus docente? A intenção do mercado pode determinar os objetivos da academia e moldar a intenção, formação e vocação docente? A representativa figura acadêmica deste pesquisador pode ser reduzida a um objetivo econômico específico dentro de uma visão instrumental tecnológica? A pesquisa acadêmica "estatal(izada)" é voltada e fomentada unicamente para a obtenção de inovação e tecnologias? Paralelamente a este fenômeno, observa-se que a formação do ensino superior no stricto sensu, ou no mestrado e doutorado, tem a intenção de abastecer de mão de obra especializada o mercado empresarial. Esta mão de obra é realmente absorvida pelo mercado empresarial?

Investir na educação é desenvolver o país? Mas o investimento na economia quem está fazendo é a educação! Pois, está investindo toda a sua capacidade de desenvolvimento que se concretiza na figura do docente pesquisador, para o alcance de tal objetivo corporativo. A questão pertinente é; estamos desen- 
volvendo "o quê" e não "quem". Estamos desenvolvendo através dos objetivos da pesquisa no PNPG (BRASIL.MEC, 2010) coisas, produtos (conhecimento útil) e não estaremos contemplados com a formação do sujeito, seja ele na figura do docente ou discente. Onde estará o espaço, ou, lugar para a formação da massa crítica, uma discussão para a (trans)formação social? Possivelmente, dentro da discussão acadêmica e olhar crítico na área de educação?

Atualmente, um meio buscado por diversas nações para a adaptação às crescentes exigências do mercado global tem se pautado na (re)valorização da educação no aspecto global e na especificidade profissional, que tem sido vista como um elemento estratégico para a promoção da competitividade dos países. Segundo a análise de Machado e Bianchetti (2011), como "prêmios de consolação" ao docente pesquisador ou como é chamado no trabalho referente, o trabalhador-pesquisador, surge "a escalada ascendente do Brasil nos rankings internacionais de produção científica" como uma maneira de "prestígio" profissional.

Para Imbernón (2009), "na docência e na inovação universitária o contexto imediato é a universidade", esta instituição está dentro do processo de mudanças sociais e globalização determinada pelos modelos de desenvolvimento econômicos vigentes e a sua maneira de gestão e controle acadêmico, através de indução pelas políticas e fontes de fomento voltadas para o atendimento de demanda da iniciativa privada. Deve-se "analisar criticamente o que há dentro e fora de suas fronteiras para renovar-se em uma nova universidade", para se obter uma visão crítica do objetivo social da universidade em relação a "ciência da cultura dominante", e repensar o modelo atual de produção acadêmica, "ainda assim, essas mudanças não podem pecar pela ingenuidade", devem entender o contexto da economia globalizada e a padronização do modo de produção acadêmica e o consequente resultado de suas pesquisas.

Bozeman e Sarewitz (apud DIAS SOBRINHO; DAGNINO, 2007, p. 5),

questionam a validade de argumentações fundamentalmente econômicas (como é o caso do enfoque evolucionário) no que se refere a políticas tecnológicas e, particularmente, a políticas científicas. Apoiadas exclusivamente em argumentos de caráter econômico, essas políticas são afastadas de questões de conteúdo político ("por que?", "para que?", "para quem?”, etc.), de relevância fundamental. Para os autores, a crença de que os investimentos em ciência e tecnologia trarão somente benefícios para a sociedade justifica a preocupação exclusiva com a geração de mais ciência e mais tecnologia. Reconhecer os aspectos negativos vinculados ao avanço científico e tecnológico seria, portanto, o primeiro passo no sentido de 
incorporar outros tipos de valores ao processo decisório na esfera da política científica e tecnológica. [...] Portanto, o avanço tecnológico (representado pelas inovações tecnológicas) continua sendo, para a abordagem evolucionária, condição suficiente para a promoção do desenvolvimento econômico e social.

Em particular nos países em desenvolvimento, a educação, dentro da visão evolucionista, tem sido apontada como um caminho para se implantar um novo papel ao qual o conhecimento e a educação combinados relacionam-se com a difusão de novas tecnologias, novos padrões de gestão do trabalho, de organização da produção e o que alguns autores denominam de economias baseadas no conhecimento, que por serem fortemente apoiadas no uso intensivo do saber, requereriam uma parcela maior de trabalhadores qualificados e capazes de envolverem-se ativamente na resolução de problemas. Segundo Wittaczik (2008), o surgimento de novas tecnologias no mercado fomentou expressivas mudanças no setor produtivo, de modo que as mudanças a serem implantadas na área educacional deveriam estar em sintonia para dar conta dos desafios que a modernidade, de modo particular, tem apresentado cotidianamente na dinâmica econômica.

Estes desafios propostos pelo setor produtivo "desafiam" ou "seduzem", em relação à adequação da educação ao modo capital de produção acadêmica, também chamada de produtivismo acadêmico, isto é, a intensificação da função universitária na realização de pesquisa a fim de estimular a competitividade econômica do país, conforme preconiza o PNPG. Na concepção hegeliana podemos entender que a consciência-de-si, percebe o ser como sujeito e não como coisa. O processo de reificação, ou coisificação do conhecimento acadêmico como produto, não como saber, condiciona docentes, mestrandos e doutorandos como produtores. Esta concepção está fomentada e regulada pela CAPES via PNPG (BRASIL.MEC, 2010), podendo induzir a academia e suas várias áreas de conhecimento para a constituição de uma massa social acrítica e formatada.

Com uma visão crítica através do olhar da área da educação, em uníssono com a filosofia, pode-se então contribuir com um entendimento sobre as diretrizes e o cenário da Pós-Graduação Brasileira, no intuito de elucidar os rumos da pesquisa acadêmica, sua política de produção, produtividade, missão e metas para o desenvolvimento econômico e social do país. Uma das questões que podem ser levantadas nesta discussão é de que o conhecimento da academia, no caso a pesquisa acadêmica, e a formação dos pesquisadores, necessariamente, estão caracterizados como "alavanca", ou seja, uma ferramenta 
estratégica para o desenvolvimento econômico segundo o Plano Nacional de Pós-Graduação (BRASIL.MEC, 2010).

Nessa relação entre notáveis pesquisadores, grandes empresas e atores dos Estados se estabelecem os temas prioritários de pesquisa e os critérios de produção e avaliação do conhecimento "útil". A economia globalizada é movida em grande parte pelo conhecimento, especialmente pelo conhecimento aplicável e útil para as empresas. É importante para essa economia que amplos setores da população, em diferentes níveis, se apropriem dos conhecimentos aplicáveis para aumentar a base de produção e de consumo dos produtos industriais (DIAS SOBRINHO, 2010, p. 1234).

Portanto, relativo à formação dos pesquisadores da Pós-graduação Brasileira, "ao assumir a tarefa de formar os novos pesquisadores, a CAPES foi compelida a investir na formação de mestres e doutores para as áreas do conhecimento consideradas estratégicas para o desenvolvimento econômico e social do País" (BRASIL.MEC, 2010, p. 156).

Nas últimas décadas, vários países deflagraram processos de reforma do ensino geral e técnico-profissional e, embora semelhanças possam ser identificadas, o sistema adotado em cada país está intimamente ligado às suas trajetórias, formas de atuação do Estado, estrutura industrial, desenvolvimento tecnológico, sistema educacional e à visão que se tem sobre o papel do conhecimento e educação no desenvolvimento econômico. Por outro lado, as analogias poderiam ser explicadas pelo fato de que nações, desenvolvidas e em desenvolvimento, encontram-se, evidentemente que de forma assimétrica, inseridas em um processo de internacionalização crescente da economia, tem produzido mudanças tanto no sistema produtivo, quanto nas exigências sobre a força de trabalho.

Diante desse contexto, o presente trabalho tem como objetivo principal realizar uma análise crítica sobre o planejamento e objetivos e regulação da pesquisa e formação na pós-graduação brasileira, que emprega a teoria econômica neoschumpeteriana/evolucionista na definição dos rumos desse sistema. Para isso, este artigo busca por meio de revisão bibliográfica levantar os principais pontos de vista de pensadores evolucionistas sobre o conhecimento e desenvolvimento econômico e confrontá-los com pensamentos dos expoentes clássicos e autores modernos da área da educação, além de avaliar o contexto do sistema nacional de avaliação da pós-graduação no Brasil embasando-o teoricamente. Todavia, ressalta-se que nem todos os autores neoschumpeterianos aqui analisados dedicam-se exclusivamente ou privilegiam o tema da 
educação em seus trabalhos, porém foram escolhidos por se acreditar que seus estudos contribuíram para difundir uma nova visão sobre os nexos entre educação e desenvolvimento econômico, acabando por embasar o PNPG.

Dessa forma, o trabalho tem seu início por esta parte introdutória de explanação, na medida em que, posteriormente apresenta a visão da corrente neoschumpeteriana do conhecimento e suas funções no ambiente acadêmico, em detrimento da ótica da educação e do sujeito na concepção hegeliana, este, como docente, ator fundamental na constituição do ser e do saber.

\section{A VISÃO EVOLUCIONISTA SOBRE CONHECIMENTO E DESENVOLVIMENTO ECONÔMICO: A UNIVERSALIDADE DA UNIVERSIDADE?}

\subsection{Investir na produtividade econômica da pesquisa acadêmica é desenvolver o país?}

A partir de uma visão evolucionista como vamos observar a seguir, verificam-se certos desdobramentos do conhecimento que veem se refletir no desenvolvimento econômico, onde se busca um embasamento para definir a inovação, no caso tendo a pesquisa acadêmica, como fator estratégico para alavancar o crescimento da economia.

Nesse sentido, Schumpeter (1957) incorporou o processo de inovações em sua teoria do sistema econômico ao afirmar que a inovação provocaria uma ruptura no sistema de (des)equilíbrio perfeitamente competitivo do mercado (representado pelo fluxo circular, no qual a vida econômica ocorre de forma semelhante ano após ano), de forma a estabelecer fontes de diferenciação para as empresas e revolucionar as estruturas produtivas no processo de crescimento econômico. Trata-se de uma "destruição criadora" motivada por inovações que os empresários, em caráter empreendedor, realizam para manter a competitividade.

A visão schumpeteriana incorpora à economia o papel dos empreendedores, no nível das inovações tecnológicas. É indispensável à ideia de um comportamento inovador, que crie condições favoráveis de mudança, para que a economia desenvolva-se, com a geração de emprego e renda para a população. Assim, a inovação constitui um determinante fundamental da dinâmica econômica, sendo, ao mesmo tempo, fundamental para definir os padrões de competitividade econômica, em especial no atual quadro de aumento da competitividade local (interna), regional e global. 
Seguindo com a hermenêutica do processo econômico-educacional, de acordo com Dathein (2000), a análise schumpeteriana revela que as mudanças na evolução econômica, além de serem adaptadas de acordo com o momento do ciclo econômico que se está vivendo, geram modificações e atualizações teóricas, principalmente na área científico-tecnológica.

A corrente neoschumpeteriana ou evolucionista completa a abordagem schumpeteriana, visto que, enquanto esta avalia as inovações de uma maneira geral, aquela formula teorias específicas, enfatizando a inovação tecnológica e todo seu contexto econômico. Embora com enfoque e objetivos diferentes, a abordagem evolucionista, ao endogeneizar o progresso técnico em seu modelo de análise do desenvolvimento econômico, acaba por voltar seu foco ao estudo da inovação procurando compreender a sua dinâmica, de maneira jogar sua luz sobre a importância da educação para o processo inovativo, e consequentemente ao progresso tecnológico (ALMEIDA, 2000). De acordo com Amorin (2007), a inovação é a mola propulsora do crescimento econômico. Segundo o autor, as necessidades de conhecimento e aprendizado daí decorrentes tornam-se dependentes do desenvolvimento das capacidades dos indivíduos que, por sua vez, tem como ponto de partida a educação.

Assim a revalorização da educação e da qualificação observada atualmente está vinculada ao papel que lhes é atribuído no aumento da competitividade de países que lograram posições privilegiadas na economia mundial. A educação passa a ser vista, também, como um condicionante do processo inovativo, o que se torna especialmente importante em um período em que as vantagens comparativas residem, cada vez mais, na capacidade de inovar em produtos e processo (ALMEIDA, 2000).

Nelson e Winter (1982) também apontam na mesma direção ao reconhecerem a existência de regras ou rotinas comportamentais diferenciadas que orientam as decisões de inovação dos agentes econômicos. Dessa maneira, os autores revelam que para a redução da incerteza referente à evolução econômica as atitudes das firmas deveriam seguir determinadas rotinas, que surgiriam da combinação do conhecimento formal com o aprendizado adquirido pelos indivíduos ao longo do tempo, na busca de realizar melhor as diversas atividades e inovações. Dessa forma,

os autores neo-schumpeterianos rejeitam o paradigma do equilíbrio característico da análise neoclássica, propondo para o seu lugar o estudo da interação endógena entre estratégia (da firma) e estrutura (do mercado) ao longo do tempo a partir dos esforços inovativos 
das empresas, onde o desequilíbrio é a regra. A concorrência passa a ser pensada como um processo dinâmico incessante, endógeno ao sistema econômico, capaz de gerar instabilidade estrutural, e no qual a diversidade e as assimetrias competitivas são características permanentes (GRASSI, 2002, p. 12).

Salienta-se, contudo, que do ponto de vista neoschumpeteriano, as inovações introduzidas, embora sejam geradas em núcleos baseados em conhecimento e aprendizado, costumam ter uso bastante difundido, haja vista que o caráter genérico das tecnologias se refere às possibilidades de sua aplicação não só nos ramos ou setores em que foram desenvolvidas, mas também em um amplo leque de atividades com repercussões em todo o tecido econômico e social (CAMPOS, 2004).

Já Perez (1986) afirma que a expressão "paradigma técnico-econômico" definiria melhor as transformações ocasionadas pela criação de novas tecnologias, na medida em que elas alteram não só as áreas de produtos e processos, mas também a estrutura de custos dos insumos, as condições de produção e a gestão das firmas. Ainda segundo a autora, em um paradigma técnico-econômico há sempre um insumo que desempenha papel central - que ela denomina de fator-chave - como foi o caso, por exemplo, do carvão, do aço e do petróleo (fatores-chave dos paradigmas técnico-econômicos anteriores ao microeletrônico). No caso das atuais tecnologias, essas considerações são preenchidas pela microeletrônica (através do uso, por exemplo, do microprocessador). A autora ainda lembra que em qualquer paradigma econômico, o encontro de um fatorchave ou a transição de um para o outro somente é possível através do progresso técnico, oriundo de sistemas de conhecimento e aprendizado cumulativo.

Portanto, tal fator-chave estaria relacionado diretamente à intensidade de aprendizado adquirido, estabelecida pelas características dos paradigmas tecnológicos em torno dos quais o aprendizado pode ser distribuído numa função matemática, distribuída graficamente (DOSI; TEECE; WINTER, 1992), conforme figura1, na próxima página.

Este gráfico evidencia a conclusão dos evolucionistas de que o tipo de base de conhecimentos envolvida nas capacitações tecnológicas é fundamental no formato e na distância em relação à origem da curva que define as fronteiras do aprendizado.

Dentro da concepção do PNPG (BRASIL.MEC, 2010, p. 195) para o decênio 2011-2020, a pesquisa acadêmica na universidade está atrelada ao desenvolvimento tecnológico econômico. "A pesquisa como sabemos foi incorporada à universidade apenas no início do século XIX, quando da criação, em 
Figura 1 - Domínio de aprendizado do ambiente econômico

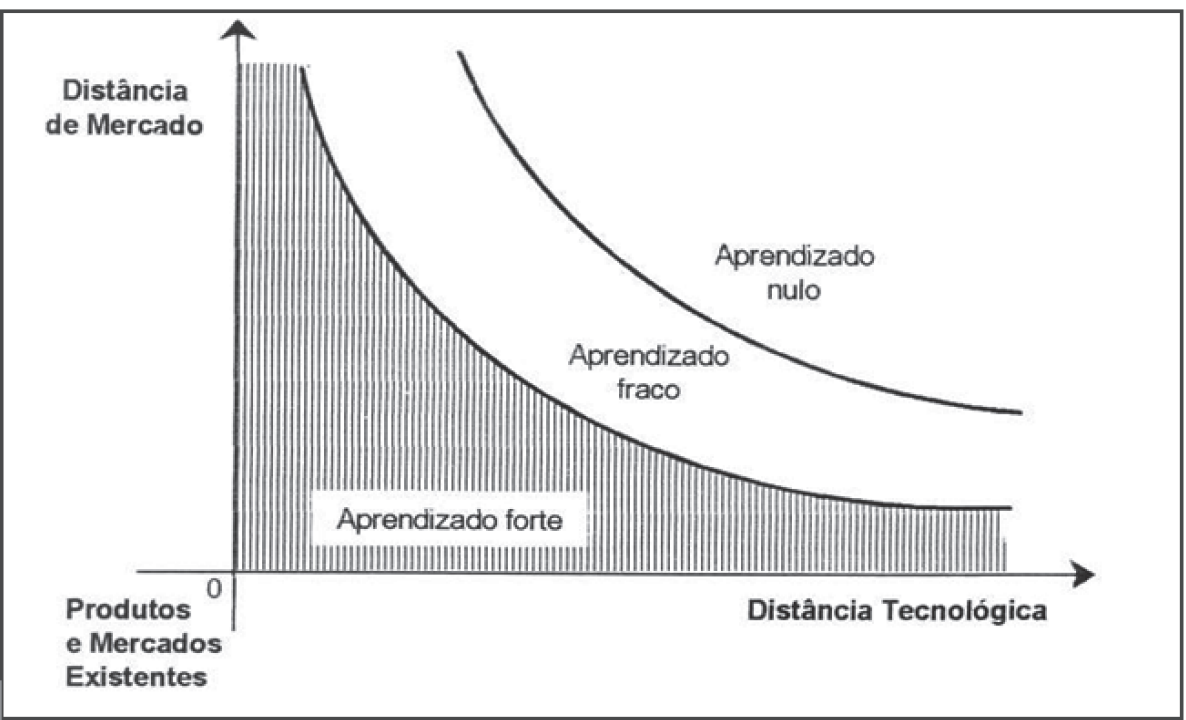

Fonte: DOSI, Giovanni; TEECE, D.; WINTER, Sidney Graham. Toward a theory of corporate coherence: Preliminary Remarks. In: DOSI, G., GIANNETTI, R. e TONINELLI, P. A. (Eds.) Technology and Enterprise in a Historical Perspective. New York: Oxford University Press, 1992.

1810, da Universidade de Berlim", o perfil da pesquisa nesta época não estava ligado às coisas práticas, existindo um distanciamento entre o que a "instituição universitária" utilizava como objeto/sujeito de sua pesquisa e "o mundo que a rodeia" onde a "indústria então existente não realizava pesquisa", estando "ao sabor do acaso ou da inventividade prática". Com o pioneirismo no desenvolvimento tecnológico "foi a indústria química alemã a primeira a se dar conta de que as descobertas científicas podiam iluminar trajetórias tecnológicas e criar soluções originais para os seus problemas" (BEER, 1959). A partir destas experiências as contratações de engenheiros para encontrar as soluções de problemas e a criação de "laboratórios de pesquisa industrial" criaram condições para "o diálogo entre o aparato universitário de pós-graduação/pesquisa e a indústria". Ainda dentro da ótica econômico-evolucionista do PNPG, que norteia os objetivos da CAPES, sua avaliação e fomento, podemos perceber nesta citação a referência às primeiras experiências acadêmico-industriais, onde "laboratórios dessa natureza foram inicialmente implantados também por empresas químicas na Alemanha entre 1877 e 1883” (HOMBURG, 1992) 
trazendo assim a concepção e "os primeiros ensaios de envolvimento da pesquisa universitária no desenvolvimento tecnológico".

Na citação do PNPG (2010, p. 195) de Rosenberg (1982) e Nelson (1993), sendo estes grandes expoentes da corrente neoschumpeteriana, podemos verificar a estreita relação entre universidade, pesquisa e indústria, pelas maneiras de interação, segundo a ótica dos autores, com o objetivo de inovação e desenvolvimento econômico,

Na transição do século XIX para o século XX diversas firmas, tanto do setor químico quanto do setor elétrico introduziram laboratórios industriais semelhantes nos Estados Unidos da América. Foi ali que estabeleceram efetivamente os primeiros protocolos de cooperação entre o aparato universitário e a indústria.

Através da avaliação CAPES, pela regulação e fomento deste órgão, ocorre uma padronização na maneira como se pensa (os objetivos) e se faz (como produção) a pesquisa acadêmica no Brasil. Portanto, existe um processo "forçado" de "alinhamento e indução" nos programas de Pós-Graduação, nas diferentes áreas de conhecimento e independentemente dos focos regionais, dentro daquilo que "se espera e avalia" como "resultado" em uma visão de desenvolvimento predominantemente economicista. Nesta perspectiva de interpretação do Plano e seus desdobramentos através do viés da ótica CAPES, e seus objetivos de produção e produtividade, percebemos afirmações relativas a parceria "esperada" das universidades e empresas na pesquisa acadêmica brasileira onde,

esta permanece até hoje a forma mais vigorosa e mais fecunda forma de trabalho em comum, aquela cujo o potencial é o mais elevado, e cujo os frutos podem ser mais naturalmente apropriados pelos dois parceiros. Foi o ponto de partida e permanece verdade até agora: a empresa capaz de ter os programas mais cooperativos mais eficazes com a universidade é a empresa que realiza P\&D internamente (BRASIL.MEC, 2010, p. 195).

Esta afirmação dentro do documento que norteia os objetivos da Pós-Graduação Brasileira no próximo decênio 2011-2020, demonstra principalmente o interesse econômico na parceria entre a academia e a indústria, dentro de uma concepção de formação de produto(s) e produtor(es) em detrimento da formação de sujeitos ou de uma construção social e sua (trans)formação. Neste movimento a universidade atrela seus objetivos na pesquisa acadêmica ao 
desenvolvimento de parcerias com a indústria desenvolvendo uma forma de produção acadêmica industrial, e nisto assume riscos em relação a sua autonomia e se torna refém de objetivos e regulações externas pelo fator reificado do produtivismo acadêmico.

Segundo o PNPG (BRASIL.MEC, 2010, p. 197), “dentre outras formas de ação cooperativa, algumas universidades assumiram papéis de monitoramento de tecnologias para empresas (MOWERY; ROSENBERG, 1998)", do ponto de vista da academia como novo lugar da inovação, este foi "o fato novo que transformou as estruturas produtivas" colocando surpreendentemente a "inovação como eixo central da economia", portanto, "o que é radicalmente novo é a intensidade que ela ocorre, o lugar que ocupa na geração de riqueza, suas repercussões na organização do trabalho na educação e na cultura".

Ainda dentro da análise do documento PNPG (BRASIL.MEC, 2010, p. 198), em uma referência a Charles Baudelaire's em "Fleurs du Mal", há uma passagem dentro de uma tradução literal em explicação a inovação e o termo "novo", sendo esta, "mergulhar no fundo do abismo, Inferno ou Céu, que importa? No fundo do desconhecido para encontrar o Novo!", ressalta assim concretamente a importância dada ao tema e a sua repercussão nos objetivos do documento em questão, e consequentemente, na pesquisa acadêmica da Pós-Graduação no Brasil, através da regulação e fomento via CAPES.

No estudo realizado por Nelson (1993), defere-se que a efetividade dos instrumentos utilizados e investimentos realizados para promover a inovação - se pesquisas em universidades ou a aposta na alta tecnologia e/ou qualificação da força de trabalho - deve estar estreitamente relacionado com as especificidades de cada país e setor e principalmente com as necessidades das empresas, de modo que a interação existente entre conhecimento e empresas implica, além do desenvolvimento de pesquisas orientadas, a disseminação de informações e a resolução de problemas. Em sua conclusão, o autor destaca que a configuração do conhecimento voltada ao processo inovativo pode representar um importante determinante econômico.

Contudo, a dinâmica de uma economia baseada no conhecimento não estaria somente na educação formal adquirida, mas também na necessidade de aprendizado contínuo, tendo em vista que a inovação oriunda de novas leituras da realidade, permitidas por descobertas da ciência e tecnologia, auferidas pelo processo de Pesquisa e Desenvolvimento (ROSENBERG, 1982). Cabe ressaltar que o caráter tácito e não codificável do conhecimento incorporado 
nas pessoas e organizações (o que lhe confere uma dimensão coletiva) é um dos fatores explicativos do caráter não aleatório do progresso técnico, o qual é representado pelo processo de cumulatividade do aprendizado (BAPTISTA, 1997). Dessa forma,

o desenvolvimento de um aparato de conceitos e definições capaz de oferecer um instrumental adequado para análise, [...] só pode ser o resultado da expansão e maturação dos vários programas de pesquisa e desenvolvimento hoje existentes (PONDÉ, 2005, p. 122).

Destarte, a faculdade de inovar de um arranjo institucional estaria ligada a sua capacidade de convergência na formação de soluções coletivas e criativas para colocar em ação as transformações necessárias, de maneira a fazer disparar os efeitos do aprendizado, que não são espontâneos e nem automáticos (FELIPE, 2008). "O caráter social e coletivo do aprendizado compreende um processo através do qual a repetição e a experimentação propiciam o desempenho melhor e mais rápido de tarefas e a identificação de novas oportunidades de produção [...]" (DOSI; TEECE; WINTER, 1992, p. 191).

DOSI (1988) corrobora nesse sentido ao revelar que a dinâmica da inovação, base do processo de transformação econômica, depende não só dos recursos destinados para esse fim, mas, sobretudo, do processo de aprendizagem (que é cumulativo, sistêmico e idiossincrático) e da difusão da tecnologia. Ainda de acordo com o autor, a base da aprendizagem estaria no conhecimento gerado pelo processo de pesquisa e experimentação tecnológica (também conhecidas por processo de $\mathrm{P} \& \mathrm{D}$ ) realizada pelas agências públicas ou universidades e a difusão tecnológica estaria fundamentada na consolidação dessa pesquisa e experimentação dentro do ambiente empresarial, ou seja, a criação de novos produtos e/ou processos (inovações).

Freeman (1974), outro expoente neoschumpeteriano, foi quem primeiro apontou para a importância de um sistema organizacional de inovação baseado em Pesquisa e Desenvolvimento (P\&D) para o fomento do progresso tecnológico. Segundo este autor, trata-se de reconhecer a importância de uma rede de instituições públicas e privadas, dentro de uma economia. Esta rede dinâmica permitiria financiar e executar as atividades inovadoras (projetos). Estas traduzem os resultados (produtos) do conhecimento em P\&D em inovações e interferem na difusão de novas tecnologias. Em síntese, os neoschumpeterianos demonstram que a educação deve estar de acordo às exigências de 
mercado (empresas) e voltada à formatação de empreendedores geradores de processos inovativos que levem à criação produtos (processos, firmas) com vistas ao desenvolvimento econômico.

Figura 2 - Concepção neoschumpeteriana para a dinâmica do desenvolvimento econômico (adotada pelo PNPG).

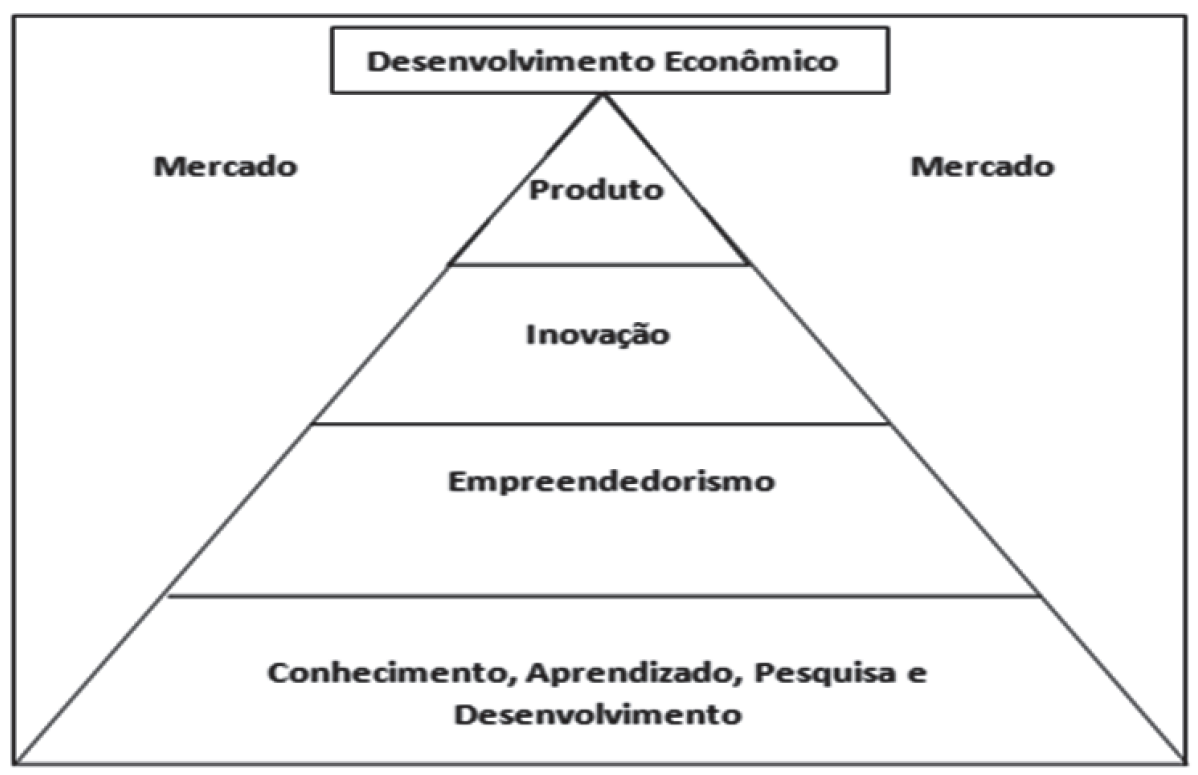

Fonte: Próprio autor

Assim, o processo de acumulação, experimentação e investigação contribui para um conceito schumpeteriano denominado de "sistema de equilíbrio perfeitamente competitivo do mercado", ao pressupor que, a concorrência é um fator inerente ao tão desejado processo de competitividade, onde toda a inovação produzida (produto) é abarcada pelo mercado. Sendo assim, está instaurada academicamente a competição pela produção acadêmica, seja ela inter/intrainstitucional ou inter/intranacional, vinculada unicamente ao resultado econômico. Há a instituição política da universidade como empresa pública de produção acadêmico-econômica e criação potencial do multinacionalismo de produção e gestão estratégica do capital acadêmico. Instituições fortes, financiadas pela iniciativa pública tendo como meta a publicação de pesquisas acadêmicas e produção de mão de obra para o setor privado. Publi- 
cação qualisada e impactada, voltada às revistas internacionais de excelência, tendo como fim, a inserção do Brasil no mercado acadêmico privado e globalizado. A academia com a sua maior riqueza, o conhecimento, este, consequente da universalidade, se torna instrumental, uma ferramenta econômica a serviço do estado, reduzindo seu "universo" à produção, para atender o mercado empresarial e a evanescente melhoria no ranking de status, em relação a outros países. Fecham-se então os olhos da academia para as suas riquezas.

Padronizam-se os processos de produção e produtividade, e neles os sujeitos "coisificados" ou "cegados", cerceados de sua universalidade e visão crítica para uma (trans)formação social, que é muito "cara" para o Brasil e a latinoamérica.

Obtém-se o mesmo resultado colocando um cego entre as riquezas do mundo supra-sensível (se é que as tem, quer se trate do conteúdo próprio desse mundo, quer da consciência desse conteúdo), ou então [pondo] um homem que tenha visão no meio das trevas puras, ou, se preferem, da pura luz (caso o mundo supra-sensível seja isso). O homem que tem vista enxergará tão pouco em sua luz quanto em suas puras trevas - exatamente como o cego na abundância das riquezas que se estendem diante dele (HEGEL, 1992, p. 124).

Essa teoria evolucionista de desenvolvimento econômico foi absorvida pelo PNPG, tendo este, como objetivo principal, norteando o planejamento e execução de metas e escalonamentos em rankings de produção, regulados pela CAPES, dentro da sua visão de resultado para a academia. Este plano tem previsão para a sua execução no período de 2011 a 2020, portanto, impactando nos objetivos acadêmicos, fomento e avaliação dos programas da Pós-Graduação Brasileira, influenciando internamente nas IES a pesquisa e a maneira de produção docente e discente. A partir disso, quais serão as consequências?

Para Dias e Dagnino (2006, p. 19),

o conhecimento gerado pelo complexo público de educação superior e de pesquisa não está sendo absorvido pelo setor produtivo e, portanto, não está sendo convertido em novos bens e serviços que poderiam trazer incrementos de bem-estar para a sociedade.

Nesta afirmação dos autores, percebe-se que a indução da criação de "produtos" e parcerias na pesquisa acadêmica, pode não trazer o "resultado" esperado no PNPG e regulado pela CAPES, para a interação universidade-empresa e menos ainda para aspectos de (trans)formação social. O modelo produtivo 
de "países desenvolvidos" parece não se adequar a realidade brasileira ou latino-americana, estas, possuem formação cultural, diferenças sociais e realidades diferentes daquelas que são "modelos" para as políticas públicas de produtividade e inovação na academia. Para tanto, não se pode somente "imitar o que se está fazendo" e "está dando certo", contestavelmente defendido pelos rankings globais ou nacionais de produção com foco preponderantemente economicista Ainda dentro da visão crítica da maneira de produzir conhecimento na pesquisa, os autores que defendem que "assim, esse ciclo virtuoso que, a despeito de eventuais problemas e reduções mecanicistas aos quais está submetido, legitima e impulsiona o capitalismo nos países centrais, não está ocorrendo nos países latinoamericanos".

Dentro do contexto de discussão de Sguissardi (2008) em relação à "natureza do Estado, se predominantemente público ou privado mercantil", fica explícito o controle deste, na "relação entre regulação estatal e cultura de avaliação institucional". Neste paradigma, a "concepção de educação superior", também encontra no "modelo de expansão superior a natureza da regulação e do controle", onde, se salienta em seus objetivos corporativos a competição acadêmica e "a eficiência e eficácia típica do mercado", portanto o conhecimento acadêmico como produto mensurável.

O controle e a regulação direta nos objetivos das pesquisas nas academias, por parte da CAPES/PNPG, "causam no conjunto dos docentes e discentes, forte descontentamento com a forma como se avaliam os programas e suas produções". Dentre os equívocos do processo avaliativo "o pressuposto mais equivocado" intrínseco neste processo "é o conceito de cultura e ele subjacente". A produção da cultura não pode ser apenas "uma atividade meramente especulativa" que procura de maneira produtivista "aumentar o volume de livros nas bibliotecas". Para tanto, é necessário o aprofundamento no conhecimento, para além da sua produção, buscando levar este, ao o teste do mundo, "para transformar a sociedade e a natureza, humanizando-as". A padronização de expectativas, comportamentos produtivistas e metas nas pesquisas acadêmicas, engessa a universalidade da universidade e fragiliza as instituições aos interesses da iniciativa privada, pois, "o estabelecimento detalhado de regras e normas favorece a esperteza e a educação mercadológica" (NOSELLA, 2010, p.1 81-182).

Em relação à avaliação e seus princípios, "o sistema de pós-graduação é constituído por um conjunto de universidades, com propostas e perfis diversos, tendo autonomia para criar ou fechar cursos, mas dependendo do financiamento da CAPES e do seu Ranking, que lhes atribui o selo de qualidade" (BRASIL.MEC, 2010, p. 127). 
Segundo exposto neste parágrafo pode-se verificar a profundidade do termo universidade, como experiência universal. Sendo assim, composto de uma infinidade de significações, coisas e sujeitos, não apenas voltado para uma única função econômica, já que a sociedade apresenta complexa interação e linguagem, que, entende-se como uma universalidade de experiências, relações e relacionamentos para a formação do sujeito docente como agente de (trans)formação social e não somente como "a mola propulsora" do desenvolvimento econômico, produção e inovação.

\section{A UNIVERSIDADE NA PERSPECTIVA DA PRODUÇÃO: INOVAÇÃO E PROCESSO DE FORMAÇÃO}

A inovação é tida como um novo paradigma no PNPG (2011-2020, p. 180) onde "o conceito de inovação, em geral, é correlacionado com pesquisa e desenvolvimento $(\mathrm{P} \& \mathrm{D})$, porém é distinto e mais amplo. Inovação implica não somente tecnologia, máquinas e equipamentos, mas vai além, contemplando também mudanças incrementais, novas funcionalidades, bem como melhorias na gestão ou novos modelos de negócios, associados à 'conquista ou criação de novos mercados".

$\mathrm{Na}$ análise de Machado e Bianchetti (2011, p. 244), surgem as "ciências humanas e sociais e seus compromissos cedo selados com governos e homens de negócio", que são avalizados pelas políticas de regulação e fomento da CAPES, com a "eleição de Educação, Ciência e Tecnologia como centrais para promover progresso econômico e social", onde, "reduziram a Universidade, predominantemente, à executora e refém, não autônoma". Ainda nesta visão percebe-se que "é o capital que precisa do conhecimento gerado pelos trabalhadores-pesquisadores para reproduzir-se, estes vivenciam a intensificação e alienação do seu trabalho; tal dependência aponta para o desafio de exercer seu poder".

Dentro do que pressupõe Sguissardi (2002, p. 242) "a estratégia de convencimento é conhecida de todos: o martelar midiático até a exaustão" mostra que a intenção das políticas de regulação é o pressionar à produção inovadora e ao atendimento das políticas de publicação em massa de produtos acadêmicos de contestável objetivo de excelência, "com apoio da sociedade assim persuadida, a promoverem as mudanças na direção recomendada".

O fator de produção, resultado e inovação, remete a pesquisa a uma visão neoschumpeteriana. Estando explicitada no PNPG, conduz lentamente ou "letalmente", os docentes enquanto pesquisadores das Instituições de Ensino 
Superior (IES) nacionais à adequação normativa de produção. Ou seja, produção técnica instrumental orientada à publicação qualisada e a formação de propriedade intelectual, visando à obtenção de royalties, em resumo, o fator acima citado para o mercado privado. Temos como meta explícita a "preparação" de mestres e doutores para a mão de obra especializada na iniciativa privada.

Hegel intenta mostrar que:

a fundamentação absoluta do saber é resultado de uma gênese ou de uma história cujas vicissitudes são assinaladas, no plano da aparição ou do fenômeno ao qual tem acesso o olhar do Filósofo (o para-nós na terminologia hegeliana) pelas oposições sucessivas e dialeticamente articuladas entre a certeza do sujeito e a verdade do objeto (1992, p. 10).

Em contraposição a visão do produto acadêmico, como objeto ou coisa, está o sujeito e a consciência-de-si segundo a visão hegeliana, e nela, a ciência, suas determinações e representações. Mas, a visão cientificista-econômica e suas metodologias epistemológicas produtivas buscam a determinação "do todo" pelo recorte, então, científico-econômico, neste movimento, abrem mão de aspectos vitais que circundam o sujeito, tratando-o como simples objeto. A simplificação da complexidade deste e suas relações podem ser buscadas para o desenvolvimento econômico como um único objetivo e finalidade, o da competição, comparação e de ranqueamento. Mas, para a visão hegeliana, o resultado por si só, é morto e inefetivo.

Por conseguinte, o que importa no estudo da ciência é assumir o esforço tenso do conceito. A ciência exige atenção ao conceito como tal, às determinações simples, por exemplo, do ser-em-si, do serpara-si, da igualdade-consigo-mesmo etc, já que esses são puros automovimentos tais que se poderiam chamar de almas, se não designasse seu conceito algo mais elevado que isso. Para o hábito de guiar-se por representações é molesta a interrupção que o conceito nelas introduz; sucede o mesmo com o pensar formal que raciocina ziguezagueando entre pensamentos inefetivos (HEGEL, 1992, p. 53).

A busca da consciência-de-si ou como entendemos, autoconsciência, passa pelo momento da autonomia e do descobrimento do pesquisador e a sua essência, que não é necessariamente, a publicação científica ranqueada mundialmente e qualisada aos objetos e objetivos econômicos. O ensino, como forma- 
ção docente pode ser o principal objeto da pesquisa, não necessariamente, o resultado morto de um recorte científico, e sim, o processo educativo in vivo e não in vitro, ao decorrer de toda a vida profissional acadêmica e pessoal, porque ambas estão intrinsecamente ligadas.

Em uma citação, Zabalsa (2003) atribui a fala a um ministro português em que "as universidades não se transformam, simplesmente há que criar outras novas"; de maneira que esta caracteriza claramente o espírito inovador que a economia dita à educação, como um todo. Neste contexto, torna explicito o instrumentalismo que está se caracterizando não só na pesquisa acadêmica e produtividade do conhecimento acadêmico, mas também na gestão política do então objeto, a "Universidade".

Esta quebra ou reengenharia acadêmica mostra claramente a visão (neo) schumpeteriana de empreendedorismo, voltada para a produção da academia como fator estratégico econômico e "destruição do antigo pelo novo". A melhoria da qualidade do ensino e da formação docente estará sendo levada em consideração? Ou avaliada e utilizada como meio para a justificação de políticas produtivas voltadas para a economia ou "à vontade do mercado"? "A inovação não é apenas fazer coisas diferentes, mas fazer as coisas melhores. [...] A questão é a introdução de processos inovadores que são assentados nas práticas e que suponham uma melhoria da qualidade daquilo que está sendo feito" (ZABALSA, 2003).

A inovação a qualquer preço pode determinar caminhos que levam a lugar nenhum, ou seja, ao esvaziamento acadêmico de conteúdo, da substancialidade. Inovar pelo inovar? Quebrar com o antigo! Estes temas "inovadores" são os objetivos corporativamente determinados pelas políticas de estado do Ministério da Educação (MEC) via PNPG que procuram a valorização econômica do país através da inserção dos objetivos da formação e pesquisa acadêmica no capital globalizado, voltado às empresas. Ou seja, dentro de uma visão schumpeteriana, o novo produto(r) acadêmico toma o lugar do velho produto(r) acadêmico e suas novas estruturas de fomento, produção e controle, destroem antigas estruturas. Assim, o progresso acadêmico-econômico seria a consequência deste processo destruidor e criativo.

Essa é a visão de Joseph A. Schumpeter, um dos principais estudiosos da área de inovação e desenvolvimento tecnológico, contemporizada posteriormente pelos neoschumpeterianos e presente nos objetivos reducionistas e economicistas da pesquisa na Pós-Graduação Brasileira.

Conforme o autor neoschumpeteriano Freeman (1995), a percepção de que o desenvolvimento das modernas tecnologias de base científica uniu a ciência 
à técnica seria uma conclusão tão verdadeira quanto a de que a introdução de novas ciências faz surgir novas tecnologias - inovações. Esta é a razão principal do porquê, segundo o próprio autor revela, a tecnologia está em grande parte sendo desenvolvida pelo trabalho de pesquisadores que têm treinamento universitário em ciência ou em engenharia. Esse entrelaçamento entre a ciência e a tecnologia, também é a razão principal do porquê, em muitos campos, a pesquisa universitária se apresenta como uma contribuinte importante para o avanço técnico, e tanto as universidades quanto os laboratórios de pesquisa incorporam partes essenciais do sistema de inovação com vistas ao interesse econômico de se desenvolver permanentemente.

Dentro desta concepção neoschumpeteriana a inovação na pesquisa acadêmica, a Pós-Graduação e a universidade cada vez mais se tornam instrumentais para a produtividade econômica e atendimento de mercado, tornando comum e "aceitável" diminuir os objetivos "autônomos" da academia para o desenvolvimento econômico de produtos e mercados.

O termo universidade tornou-se vago e abstrato. Usado e abusado até ultrapassar os limites do aceitável na denominação de dezenas de universidade corporativas no país [...] denomina hoje realidades extremamente diversas confundindo tanto o especialista quanto o homem comum. Em outras palavras, já se foi o tempo em que se podia identificar a universidade com uma instituição de profundo significado histórico, que, autônoma e "mansiio da liberdade" de pensamento, produz, conserva e distribui o conhecimento em todos os campos do saber, além de formar profissionais críticos demandados pela sociedade que os sustenta (SGUISSARDI, 2002, p. 242).

Dagnino (2009) reforça essa conclusão ao afirmar que a inovação, gerada através do processo de pesquisa nos centros de estudos tecnológicos (universidades), foi cunhada no contexto dos países de capitalismo avançado para designar um conjunto de atividades que engloba desde a $P \& D$ até as novas técnicas de comercialização derivadas de intensa aplicação do conhecimento, que tem por objetivo principal melhorar a condição de empresas e consequentemente promover o desenvolvimento econômico das nações, de modo a proporcionar através disso o "bem-estar social". Ainda conforme o autor, esse conjunto que é aqui referido mais pelos resultados que sua aplicação produz do que pelos conceitos e relações específicas que engloba, é originário da visão econômica evolucionária, também denominada de corrente econômica neoschumpeteriana.

Dentro da visão de Ibarra Colado (2003, p. 1061) o "conhecimento gerado pelo capitalismo acadêmico é apropriado e operado pelas universidades e 
seus pesquisadores", salientando o modo produtivista e globalizado, regrado na Pós Graduação Brasileira pelo processo avaliativo CAPES. Embora existam outros pontos a serem trabalhados pelo sistema, como a formação docente e discente, estes, não estão priorizados dentro da perspectiva produtivista atual, onde se valida o conhecimento util ou técnico aplicado. Nesta concepção, "a análise dos sistemas legais e organizacionais que regulam universidade-empresa-governo, a determinação dos direitos propriedade operacional, adquirem grande relevância a partir dessa perspectiva", pelo motivo do "que está em jogo é o controle, apropriação e distribuição de ativos de conhecimento, fundamental para ter sucesso na administração da concorrência global".

Temos então caracterizada a formação de um paradigma "(in)sustentável" em um sistema econômico-acadêmico retroalimentado. Por um lado, pela vocação da universidade e formação do sujeito, no caso, docente ou discente, esta concepção economicista se torna insustentável, pela reificação (TREVISAN; ROSSATTO, 2010). Dentro da estrutura acadêmico-econômico-organizacional de avaliação e fomento, através do modelo da Coordenação de Pessoal de Nível Superior (CAPES), a pesquisa acadêmica encontra a sustentabilidade financeira e a indução ao resultado "desejado" de suas políticas.

As exposições da produção, inovação e do processo de formação nos levam a perceber a figura do docente como ator principal nos processos, centralizando as ações da pesquisa acadêmica brasileira. Mas estes sujeitos, segundo o PNPG, possuem apenas as funções relacionadas ao aspecto inovador ou empreendedor, para a busca do desenvolvimento econômico e concretização das ambições das demandas da produtividade nacional da Pós Graduação Brasileiro como fator estratégico.

\section{DOCENTE OU EMPREENDEDOR: O ATOR PRINCIPAL OU COADJUVANTE NO CENÁRIO DE DECISÃO DA PESQUISA ACADÊMICA BRASILEIRA?}

Como já contemporizado anteriormente, a produção e gestão estratégica do capital acadêmico como produto, tem na figura do docente, o empreendedor, o gerador das riquezas, o provedor e detentor da produção do conhecimento acadêmico para o desenvolvimento da economia. Sendo assim, estrategicamente as políticas públicas colocam a pesquisa acadêmica e o pesquisador, como um ator reificado, um objeto, decisivo para o desenvolvimento econômico do país, como esta sendo sua única função social. 
Hoje, impõe-se uma abertura dos professores ao exterior. Comunicar com a sociedade é também responder perante a sociedade. Possivelmente, a profissão tornar-se-á mais vulnerável, mas esta é a condição necessária para a afirmação do seu prestígio e do seu estatuto social. Nas sociedades contemporâneas, a força de uma profissão define-se, em grande parte, pela sua capacidade de comunicação com o público (NÓVOA, 2007, p. 9).

Neste processo, o docente pode buscar a autonomia, também nos objetivos da pesquisa acadêmica. Ou seja, ser o ator principal na sua fala e contribuição com a sociedade, procurando a significação como "sujeito", e não mais como objeto ou coisa dentro de objetivos econômicos. Podendo assim, escrever a varias mãos, rumos diversos para a pesquisa nas áreas de conhecimento, utilizando o olhar crítico da área da educação como referência. Portanto, não figuraria mais como pretendido no PNPG, somente como o executor ou "empreendedor na pesquisa para a economia e criação de produtos", sendo assim, um coadjuvante ou executor, à margem na tomada de decisão deste sistema.

Relativo às pesquisas no campo da educação, podemos ter um paralelo com os objetivos economicistas da pesquisa acadêmica da Pós-Graduação Brasileira e suas relações com o ser e o saber, utilizando para a crítica a este posicionamento, os expoentes clássicos do pensamento e suas raízes ontológicas,

Com essa máxima concentração ou atenção seletiva direcionada apenas à questão do conhecimento, as pesquisas educacionais negaram ou restringiram o seu foco, esquecendo o reconhecimento da dimensão ontológica do problema. Os mecanismos de apropriação do saber ficaram bloqueados, pois se perdeu a fluência necessária entre elementos opinativos, epistemológicos e ontológicos. Houve, então, um empobrecimento do debate, porque foi perdido o contato com as fontes originárias do pensamento, de onde tudo brota e deveria retornar, bem como com a densidade das ideias que são produzidas em contato com as grandes matrizes teóricas do pensamento (TREVISAN; ROSSATTO, 2010, p. 283).

Para Dias Sobrinho (2010, p. 1238)

As disciplinas mais prestigiadas e que recebem mais generosos financiamentos, no atual momento da economia globalizada, são as de base técnica, como a biotecnologia, a biologia, a informática, a engenharia, a pesquisa médica, a eletrônica e outras que, com essas, compõem um campo que potencializa o processo inovativo e "a 
competitividade de um país e das empresas" (DIAS SOBRINHO, 2010, p. 1238).

Não podemos confundir, pelo produtivismo induzido via avaliação CAPES, a visão Schumpeteriana de empreendedor, com a figura do docente pesquisador, como entendemos que está pretensamente sugerido dentro do Plano Nacional de Pós Graduação, em relação à inovação. Não é somente da pesquisa qualisada que "vive" os Programas de Pós-Graduação em uma universidade, mas também de ensino e extensão, como sugere Bianchetti (2011, p. 444) a simples passagem da "formação de professores" para a "formação de pesquisadores".

Dentro desta visão, percebemos que a academia se volta quase exclusivamente para a pesquisa estatal corporativa e seu condicional de impacto econômico, descrito em seus objetivos, entre estes, o "aumento no número de doutores por mil habitantes, na faixa etária dos 25 aos 64 anos, dos atuais 1,4 para 2,8" até o ano de 2020 (BRASIL.MEC, 2010, p. 294).

Teremos na posição de pesquisadores que, unicamente, alavancar a posição econômica do país, como meta institucional? Uma universidade, local público de construção social, conhecimento, discussão, formação e "excelência", como os programas de Pós Graduação das IES, pode ser induzido pelo "apelo" ao desenvolvimento econômico para a preparação de mão de obra especializada para a as indústrias? Institui-se então a "moderna" constituição do mercado acadêmico-econômico-empresarial e a sua justificação através de índices, percentuais, rankings e estatísticas? A Pós Graduação Brasileira forma doutores como "recursos humanos" para a indústria?

Dentro da visão de Dias Sobrinho (2003, p. 94-95), contemporizado neste artigo nos "objetivos e efeitos da avaliação", no caso da CAPES, há a referência "à avaliação tecnológica, centrada na tradição objetivista empirista, e à democrática, que valoriza a participação social na construção e execução de seu projeto", não sendo "um processo autolimitado que basta a si mesmo", portanto, este processo avaliativo obrigatoriamente "lança seus efeitos sobre o sistema de educação superior e suas funções relativamente à construção da sociedade", estando "no centro das reformas e no foco das competições" que buscam a sua justificação nos "números e estatísticas de uma avaliação, que fornecem os dados básicos das hierarquizações (rankings)", que também estão inseridos dentro da visão globalizada da economia, em um "amplo horizonte social e político de grande conflitividade". 
Tabela 1 - Porcentagem de Doutores na Indústria: Recursos humanos para empresas, o papel da Pós-Graduação

\begin{tabular}{|c|c|}
\hline PAÍS & \% DOUTORES NA INDÚSTRIA \\
\hline CANADÁ & 62,2 \\
\hline ITÁLIA & 52,6 \\
\hline COREIA & 40,0 \\
\hline FRANÇA & 37,8 \\
\hline INGLATERRA & 34,7 \\
\hline ALEMANHA & 26,7 \\
\hline JAPĀO & 14,2 \\
\hline USA & 7,7 \\
\hline CHINA & 7,4 \\
\hline BRASIL & 7,1 \\
\hline
\end{tabular}

Fonte: BRASIL. Ministério da Educação. Coordenação de Aperfeiçoamento de Pessoal de Nível Superior CAPES/MEC. Plano Nacional de Pós-graduação (PNPG) 2011-2020, Brasília, 2010. v. 1.

Dentro da previsão do número de doutores no ensino superior podemos observar a perspectiva de crescimento numérico destes em curto prazo, como meta que o país nunca teve. Mas, percebendo que as metas inovadoras induzem à produção voltada para as metas estatais de desenvolvimento econômico, estes novos pesquisadores em potencial não estariam, se não absorvidos pela iniciativa privada, adentrando o ensino superior com a "resiliência" do produtivismo acadêmico como único modo conhecido de produção? Estes, não iriam (re)produzir o conhecimento da mesma maneira que foram induzidos a construí-lo? Para o atendimento da demanda do mercado acadêmico industrial, inovação e desenvolvimento econômico do país? Formaremos assim um ciclo contínuo tendendo a retroalimentação e a industrialização dos objetivos, e, da academia. Uma indústria de excelência produtora de recursos humanos especializados. Estes doutores iriam trabalhar na indústria e o que aconteceria com os programas que estão situados longe dos grandes centros industriais como o centro sul? A demanda de doutores voltados para a indústria é tão grande e diversa que absorveria as outras áreas de conhecimento que não as técnicas científicas? Ou, a mão de obra especializada promulgada no PNPG (BRASIL.MEC, 2010) é somente para aquelas áreas que conseguem produtivizar o conhecimento? 
O que faria um discente em formação ou docente pesquisador doutor em filosofia, educação ou sociologia? Transformaria o sujeito em objeto? Reificaria o ser em um produto para atender o mercantilismo?

\section{Tabela 2 - PNPG e a previsão do número total de docentes no ensino superior - 2010 a 2013}

\begin{tabular}{|c|c|c|c|}
\hline Ano & LI & Previsão & LS \\
\hline 2010 & 56.070 & 59.946 & 63.821 \\
\hline 2011 & 56.771 & 62.621 & 68.472 \\
\hline 2012 & 57.672 & 65.297 & 72.921 \\
\hline 2013 & 58.631 & 67.973 & 77.314 \\
\hline
\end{tabular}

Fonte: BRASIL. Ministério da Educação. Coordenação de Aperfeiçoamento de Pessoal de Nível Superior CAPES/MEC. Plano Nacional de Pós-graduação (PNPG) 2011-2020, Brasília, 2010. v. 1. Obs.: LI e LS são, respectivamente, o limite inferior e o superior do intervalo de previsão de $95 \%$.

Segundo o descrito no PNPG (BRASIL.MEC, 2010), "os objetivos da pós-graduação entre os anos de 2005 e 2010 foram: o fortalecimento das bases científicas, tecnológica e de inovação; a formação de docentes para todos os níveis de ensino e a formação de quadros para mercados não acadêmicos". Portanto, estamos em um processo histórico institucional de alinhamento organizacional acadêmico. Estes, voltados também internamente nas IES para a obtenção de "lucros acadêmicos através da pesquisa", dentro de uma visão reducionista da pesquisa, da própria universidade e seu corpo docente, tendo como objetivo reificado, o desenvolvimento da economia a competência e a competitividade.

No que concerne à produção do conhecimento científico, podemos considerar o início deste século como um momento positivo para o Brasil. Isso é demonstrado pelos "indicadores cientométricos" de produção de artigos em periódicos indexados, que triplicou em quantidade nos últimos dez anos. Isso graças aos investimentos feitos na pós-graduação nos últimos cinquenta anos pela CAPES e pelo CNPq. Em razão das ações dessas instituições, esse índice alcançou em 2009 a marca de 2,6\% da produção mundial. Entretanto, apenas a melhoria dos indicadores de produção científica indexada dos últimos anos não basta para fazer com que "o Brasil mude de patamar 
de forma consistente" e se transforme numa das lideranças científica e tecnológica do cenário internacional. Para que isso aconteça, a pósgraduação exerce papel primordial, promovendo avanços como um dos vetores responsáveis por "transformar a ciência em desenvolvimento tecnológico e em inovação". Somente assim, a "competência e competitividade nacional" poderão ter como base uma "política pautada na pós-graduação" como um de seus pilares de sustentação, apta a garantir a continuidade do desenvolvimento social e econômico de forma sustentável (BRASIL.MEC, 2010, p. 256).

Estes objetivos dispostos acima, claramente direcionam o docente e a universidade, através da pesquisa, para o produtivismo acadêmico, competitividade entre IES e entre pares.

Pode-se caracterizar então esta disputa individualizada, como um meio para seduzir a política interna das IES? E consequentemente, o docente à aceitação da regulação em benefício do fomento e em detrimento da criação de uma alternativa crítica-colaborativa ao sistema vigente, e assim, às regras do jogo estatal-acadêmico-empresarial, que são ditadas unicamente pela "visão estatizada" do setor econômico-empresarial.

Dentre os "cenários" que compoem a universidade e a pesquisa acadêmica, "no entanto, o que é importante é reconhecer a presença crescente do capitalismo acadêmico em áreas do nosso sistema universitário e estar preparado para discutir propostas e iniciativas, tendo a capacidade de imaginar cenários diferentes que nos permitam construir um sistema de produção de conhecimento que atenda às necessidades da sociedade e não apenas os da economia" (IBARRA COLADO, 2003, p. 1066).

Diante do exposto, compreendemos a complexidade de objetivos e importância da pesquisa acadêmica nas instituições e o atual cenário da pesquisa da Pós-Graduação Brasileira, envolvendo uma série de interesses, entre eles, e não somente para a educação ou transformação social, o "latente" desenvolvimento econômico do país.

\section{ASPECTOS CONCLUSIVOS}

Embora possamos perceber a evolução estatística na produção científica no ranking mundial, no número de mestres, doutores e na produtividade geral da Pós-Graduação no Brasil, percebemos o direcionamento que está tomando a sua política de fomento e regulação, ou seja, a pesquisa acadêmica como 
fator estratégico para alavancar o desenvolvimento econômico do país (visão econômico-evolucionista).

Os números e índices cientométricos (BRASIL.MEC, 2010) representam a justificação para a indução estratégica da pesquisa acadêmica e do docente à criação de produtos, que possuam valor no mercado empresarial, sejam eles papers, livros ou a mão de obra especializada de mestres e doutores, "formados" com o exclusivo intuito de atendimento de demanda do mercado acadêmico-empresarial e desenvolvimento econômico.

O Estado, através do sistema de avaliação CAPES e objetivos de desenvolvimento do PNPG (BRASIL.MEC, 2010), pressiona à produção e induz a pesquisa através da regulação, ao mesmo tempo que aprisiona seu universo e seus objetivos através do fomento a academia. Consequentemente, formata o perfil docente, às metas da produtividade acadêmico-econômica, em detrimento, por exemplo, do ensino e extensão das Instituições de Ensino Superior (IES).

O desenvolvimento econômico e os mecanismos que a lógica economicista utiliza, portanto são; o alinhamento, avaliação/regulação/fomento (dentro do mesmo órgão de controle), a indução de produção e produtividade por este meio, e o "descarte" da produção que ocorre após a avaliação trienal dos programas, ou seja, a "destruição da antiga produção acadêmica" pela "nova produção acadêmica", demonstrando a característica schumpeteriana da inovação.

A Educação Universitária Brasileira é baseada nos três pilares acadêmicos, ou seja, no tripé, ensino, pesquisa e extensão. Faltaria, dentro da ótica do "evolucionismo acadêmico" e da concepção "inovadora", um "quarto" pilar: o desenvolvimento econômico? Pode se presumir, então, uma tendência de aumento da disponibilização do percentual do Produto Interno Bruto (PIB) brasileiro, destinado a Educação? Então, se este é um ponto estratégico, consequentemente deve receber incentivos substancialmente maiores do que estão disponibilizados atualmente, não somente de metas a serem alcançadas, para o desejado "crescimento da pesquisa acadêmica" e das Instituições de Ensino Superior (IES) no Brasil, como um fator de desenvolvimento econômico.

No alinhamento ou padronização CAPES, se colocam os programas e propostas de produção, dentro dos mesmos critérios e análises, para favorecimento de uma avaliação linear, pretensamente qualitativa e objetiva, para diversas áreas de conhecimento, independentemente também da regionalidade e tempo de criação destes.

Trabalhando como previsto no PNPG (BRASIL.MEC, 2010), a partir da visão neoschumpeteriana de inovação, da ciência e tecnologia, estaremos ca- 
minhando cada vez mais para nos tornarmos empresas públicas de produção acadêmica e desenvolvimento econômico de estado, reduzidas a objetivos instrumentais-tecnológicos. Deixaremos de ser universidade e universalidade? Ao mesmo tempo, seremos "formalizados" e alinhados como empreendedores ou pesquisadores-executores de políticas de estado, mais distantes da visão hegeliana do sujeito, reificados como produto (s) e produtor(es).

Dentro do olhar crítico da educação, se os objetivos da pesquisa acadêmica na pós-graduação brasileira estiverem reduzidos ao "lema estatal" de produzir para atender ao mercado econômico-empresarial, estaremos assim, reduzindo as suas possibilidades, o seu universo, portanto, a formação do sujeito consciente-de-si. Estaremos apenas executando planos, alcançando metas, melhorando rankings e demandando mão de obra para o mercado, abrindo mão da construção colaborativa de objetivos (trans)formadores da sociedade. Não temos a certeza que a mão de obra demandada de mestres e doutores será absorvida pelo mercado.

Este sistema evolucionista econômico aplicado à pesquisa acadêmica pode cada vez mais amordaçar, ou criar o silêncio docente, em relação à voz crítica. Formadores de opinião cada vez mais empreendedores, a serviço do desenvolvimento econômico do Estado. Relevam-se então ao posto de "objetivos secundários" o ensino, a extensão e os conhecimentos acadêmicos voltados para a sociedade como um todo, transformando especificamente o saber acadêmico desenvolvido na Pós Graduação Brasileira, para a forma única de um produto. Essa visão pragmática das políticas educacionais ao se disseminar amplamente sem as devidas ressalvas pode levar àquilo que Merton (1970 apud ALTER, 2001), um weberiano pouco afeito ao questionamento das relações de produção capitalistas neoschumpeterianas, preconiza em sua ideia sobre o espectro da busca pela inovação nas nações. Para ele, "entre as sociedades de nível social e econômico elevado, não é raro que a pressão em favor da inovação torne imprecisa a distinção entre as práticas regulares e irregulares", "morais e imorais", de maneira a sucumbir assim à formação da autoconsciência e caráter do individuo.

Através do simples acolhimento, sem a visão crítica destes objetivos, defendida neste trabalho através do olhar da educação, os pesquisadores acadêmicos pelo fato do fomento e incentivo à pesquisa estão historicamente sendo conduzidos para a privação da autonomia e direcionamento de suas investigações acadêmicas aos interesses prioritários da economia, ao mesmo tempo em que o Estado aumenta a sua regulação e controle. Relevando assim, a formação docente, cultural e o aspecto de (trans)formação social, em detrimento do 
Figura 3 - Visão (trans)formadora dos objetivos da Pós-Graduação Brasileira através da ótica da educação

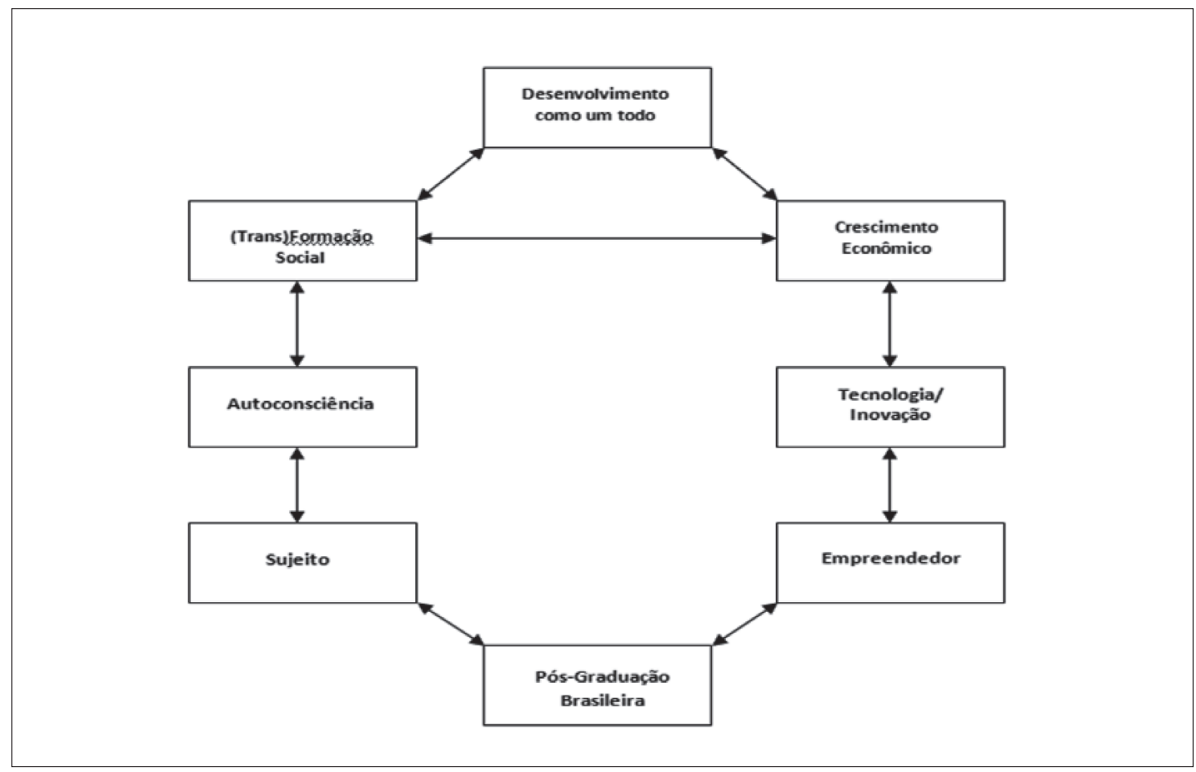

Fonte: Próprio autor

aspecto econômico e o seu desenvolvimento. Novamente a economia dita os rumos da educação, de outras áreas do conhecimento e consequentemente a função das pesquisas na academia.

Para o PNPG (BRASIL.MEC, 2010), a pesquisa acadêmica em áreas do conhecimento acadêmico é considerada ferramenta estratégica para o desenvolvimento econômico. Acreditamos o contrário, que este, é a consequência da pesquisa acadêmica, formação, educação e construção social, ou seja, o crescimento da sociedade através da evolução educacional, e não, somente da evolução econômica.

O planejamento dos objetivos da Pós-graduação Brasileira não pode estar baseado somente em tendências inovadoras e produtivistas, voltadas para o mercado e desenvolvimento econômico. Observamos que são realidades e que devemos entendê-las como uma oportunidade de (trans)formação social e não apenas de crescimento econômico em rankings de produção mundial. A formação da autoconsciência deve buscar no sujeito a opinião crítica aos modelos, que, pela necessidade exacerbada de produtividade, buscam a redução 
deste aos interesses da economia, chegando assim, a reificação do ser e do saber nos objetivos do PNPG para a academia.

Propõe-se, pois, uma maneira menos indutiva entre as partes envolvidas na Pós Graduação Brasileira, ou seja, uma visão mais universalizada e menos reducionista onde o sujeito é levado em consideração, podendo realizar uma distribuição de importância(s) mais justa(s) para a contribuição na (trans)formação social e desenvolvimento "como um todo".

Assim, concluímos que o desenvolvimento econômico tem de ocorrer "na" pesquisa acadêmica, ou seja, na universidade, e não o inverso, o desenvolvimento econômico "da" universidade dentro da pesquisa, como está sendo posto pelas políticas públicas, regulação, fomento para a Pós Graduação Brasileira e promovidas pelo Ministério da Educação (MEC).

A experiência docente e discente na investigação acadêmica, fator primordial dentro da busca do saber, formação do sujeito e transformação social, não pode ser cerceada pelo princípio e justificação do desenvolvimento econômico, senão, podemos estar reificando o ser, e ao mesmo tempo nos autoreificando, ficando cegos a riqueza do (re)conhecimento da univers(al)idade acadêmica.

\section{REFERÊNCIAS}

ALMEIDA, Maria Lemos de. A influência das teorias econômicas sobre as políticas públicas de formação profissional no Brasil nos anos 90. In: ENCONTRO ANUAL DA ASSOCIAÇÃO NACIONAL DE PÓSGRADUAÇÃO E PESQUISA EM CIÊNCIAS SOCIAIS. Anais..., Petrópolis, 2000. 1 CD-ROM.

ALTER, Norbert. Inovação, risco e transgressão nas organizações. In: DAVEL, E.; VERGARA, S. (Org.). Gestão com pessoas e subjetividade. São Paulo: Atlas, 2001.

AMORIM, Wilson Aparecido Costa. Conhecimento e aprendizagem: uma breve revisão, dos clássicos aos neoschumpeterianos. Revista Integração, São Paulo, v. 13, n. 48, p. 29-38, jan./mar., 2007.

BAPTISTA, Margarida Afonso Costa. A abordagem neoschumpeteriana: desdobramentos normativos e implicações para a política industrial. Tese (Doutorado em Economia) - Universidade Estadual de Campinas, 1997. 
BEER, John Joseph. The emergence of the German dye industry. Illinois: University of Illinois Press, 1959.

BIANCHETTI, Lucídio. Condições de trabalho e repercussões pessoais e profissionais dos envolvidos com a pós-graduação stricto sensu: balanço e perspectivas. Linhas Críticas, Brasília, v. 17, n. 34, p. 439-460, set./dez., 2011.

BRASIL. Ministério da Educação. Coordenação de Aperfeiçoamento de Pessoal de Nível Superior - CAPES/MEC. Plano Nacional de Pósgraduação (PNPG) 2011-2020, Brasília, 2010. v. 1

CAMPOS, Fred Leite Siqueira. Inovação, tecnologia e alguns aspectos da teoria neoschumpeteriana. Revista Eletrônica Administradores sem Fronteiras, Franca, n. 1, v. 1, p. 1-27, 2004.

DAGNINO, Renato. Elementos para uma teoria crítica da tecnologia.

Revista Brasileira de Ciência, Tecnologia e Sociedade, São Carlos, v. 1, n. 1, p. 3-33, jul./dez., 2009.

DATHEIN, Ricardo. O crescimento do desemprego nos países desenvolvidos e sua interpretação pela teoria econômica: as abordagens neoclássica, keynesiana e schumpeteriana. Tese (Doutorado em Economia) Universidade Estadual de Campinas, 2000.

DIAS, Rafael; DAGNINO, Renato. A Política Científica e Tecnológica brasileira: Três enfoques teóricos, três projetos políticos. In: JORNADAS LATINOAMERICANAS DE ESTUDOS SOCIAIS DA C\&T, 4., 2006, Bogotá. Jornadas..., Bogotá, 2006. p. 1-15

DIAS SOBRINHO, José. Avaliação: políticas educacionais e reformas da educação superior. São Paulo: Cortez, 2003.

. Democratização, qualidade e crise da educação superior: faces da exclusão e limites da inclusão. Educação e Sociedade, Campinas, v. 31, n. 113, p. 1223-1245, out.-dez. 2010.

DOSI, Giovanni. Technical change and industrial transformation. London: Macmillan, 1984. . The nature of the innovation process. In: et al. (Eds.).

Technical change and economic theory. London : Printer Publishers, 1988. p. 221-238. 
DOSI, Giovanni; TEECE, D.; WINTER, Sidney Graham. Toward a theory of corporate coherence: Preliminary Remarks. In: DOSI, G.; GIANNETTI, R.; TONINELLI, P. A. (Eds.) Technology and enterprise in a historical perspective. New York: Oxford University Press, 1992.

FELIPE, Edenilson Silva. As instituições e os neoschumpeterianos: a noção de aprendizado a partir do pilar cognitivo das instituições. Revista Pesquisa e Debate, São Paulo, v. 19, n. 1 (33), p. 15-32, jan./jun., 2008.

FREEMAN, Christopher. Economics of industrial Innovation. Penguin: Middlesex, 1974.

. The 'National System Innovation' in historical perspective.

Cambridge Journal of Economics, New York, v. 19, n. 1, p. 5-24, fev. 1995.

GRASSI, R. A. Concorrência schumpeteriana e capacitações dinâmicas: explicitando elos teóricos. In: ENCONTRO NACIONAL DA SOCIEDADE DE ECONOMIA POLÍTICA, 7., Curitiba. Anais...., Curitiba, 2002.

HABERMAS, Jürgen. Verdade e justificação: ensaios filosóficos. São Paulo: Loyola, 2007.

HEGEL, Georg Wilhelm Friedrich. Fenomenologia do espírito. 2.ed. Rio de Janeiro: Vozes, 1992.

HOMBURG, Stefan. Efficient economic growth. Berlin: Springer-Verlag, 1992.

IBARRA COLADO, Eduardo. Capitalismo académico y globalización: la universidad reinventada. Educação e Sociedade, Campinas, v. 24, n. 84, p. 1059-1067, 2003.

IMBERNÓN, Francisco. Formacción e inovacción en la docencia universitária en la universidad del siglo XXI. In: LAMARRA, N. F. (Org.). Universidad, sociedad e innovación. Uma perspectiva internacional. Buenos Aires: EDUNTREF, 2009. p.179-190.

MACHADO, Ana Maria Netto; BIANCHETTI, Lucídio. (Des)fetichização do produtivismo acadêmico: desafios para o trabalhador-pesquisador. Revista de Administração de Empresas, São Paulo, v. 51, n. 3, maio/ jun., 2011. 
MOWERY, David; ROSENBERG, Nathan. Paths of innovation: technological change in 20th century America. Cambridge UK: Cambridge University Press, 1998.

NELSON, Richard Rick; WINTER, Sidney Graham. An evolutionary theory of economic change. Cambridge: Harvard University Press, 1982.

NELSON, Richard Rick. National innovation systems. Oxford: Oxford University Press, 1993.

NOSELLA, Paolo. A pesquisa em educação: um balanço da produção dos programas de pós-graduação. Revista Brasileira de Educação, Rio de Janeiro, v. 15, n. 43, p. 177-183, jan./abr., 2010.

NÓVOA, A. O regresso dos professores. Conferência: desenvolvimento profissional de professores para a qualidade e para a equidade da aprendizagem ao longo da vida. Lisboa, 2007. Disponível em: <http:// repositorio.ul.pt/bitstream/10451/687/1/21238_rp_antonio_novoa.pdf $>$. Acesso em: 20 jun. 2012.

PEREZ, Carlota. Las nuevas tecnologías: una visíon de conjunto. In: OMINAMI, Carlos (Org.). La tercera revolutión industral: impactos internacionalis del actual viraje tecnológico. Buenos Aires: Grupo Editor Latinoamericano, 1986. p. 43-89

PONDÉ, J. L. Instituições e mudança institucional: uma abordagem schumpeteriana. Economia, Brasília, v. 6, n. 1, p. 119-160, jan./jun. 2005.

ROSENBERG, Nathan. Inside the black box: technology and economics. Cambridge: Cambridge University Press, 1982.

SGUISSARDI, Valdemar. Rumo à universidade competitiva: na modernização conservadora a universidade perde sua face, sua alma e sua identidade histórica. Perspectiva, Florianópolis, v. 20, n. 2, p. 239-268, jul./ dez., 2002.

SGUISSARDI, Valdemar. Regulação estatal versus cultura de avaliação institucional? Avaliação, Campinas; Sorocaba, v. 13, n. 3, p. 857-862, nov. 2008.

SCHUMPETER, Joseph Alois. The theory of economic development. Cambridge: Harvard Unversity Press, 1957. 
TREVISAN, Amarildo Luiz; ROSSATTO, Noeli Dutra. Reificação e reconhecimento: reflexões para a pesquisa em educação. Linhas Críticas, Brasília, v. 16, p. 275-286, jul./dez. 2010.

WITTACZIK, Lidiane Soares. Educação profissional no Brasil: histórico. Revista E-tech: tecnologias para competitividade industrial, Florianópolis, v. 1, n. 1, p. 77-86, jan/jun, 2008.

ZABALZA Beraza, Miguel Ángel . Innovación en la enseñanza universitária. Santiago de Compostela, España: Universidad de Santiago de Compostela, 2003. 